\title{
Structural Challenges for Improving Rural Medical Training in Germany
}

Jens Holst ${ }^{*}$ and Markus Herrmann

Institute of General Practice and Family Medicine, University of Magdeburg, Saxonia-Anhalt, Germany

*Corresponding author: Jens Holst, Institute of General Practice and Family Medicine, University of Magdeburg, Magdeburg, Saxonia-Anhalt, Hessen, Germany, Tel: +49-391-6721009; E-mail: markus.herrmann@med.ovgu.de or drjensholst@web.de

Rec date: Jan 06, 2016; Acc date: Feb 05, 2016; Pub date: Feb 07, 2016

Copyright: $\odot 2016$ Holst $\mathrm{J}$, et al. This is an open-access article distributed under the terms of the Creative Commons Attribution License, which permits unrestricted use, distribution, and reproduction in any medium, provided the original author and source are credited.

\begin{abstract}
The role and strength of primary health care $(\mathrm{PHC})$ varies considerably between countries although it has been on the global health-policy agenda for almost four decades since the Conference of Alma-Ata in 1978. A rapid international overview suggests the hypothesis that state-run or tax-borne health systems tend to face less difficulties to implement strong primary care compared to those where non-state actors play a more important or even predominant role. This paper aims at contributing to empirical evidence and system understanding of the underlying causes for countries' difficulties to strengthen PHC. Germany is an example for a healthcare system with long tradition and universal coverage of quality health services that has not yet managed to strengthen PHC. For assessing the reasons why, the paper starts with a general overview of relevant features and the rather complex structure of stakeholders in the German healthcare system, including medical training. It follows an analysis of potential system obstacles on the way towards strengthening $\mathrm{PHC}$ and particularly towards reforming medical training in order to better prepare future physicians for general practice and rural health. Finally, the paper briefly presents an innovative approach launched by the medical faculty of Magdeburg for promoting the recruitment of rural health professionals and upcoming system obstacles.
\end{abstract}

Keywords: Medical training; Rural practice; System constraints; Community-based education; Primary health care; Medical school; General practice, Family medicine

\section{Introduction}

International health system comparisons identify Germany as a country with high spending on health, providing universal health coverage, quality health services and good access to care $[1,2]$. The Federal Republic of Germany has implemented a series of equalization and compensation mechanisms in order to ensure the constitutional right of all citizens to benefit from equal living conditions all over the country. The right to health, however, is increasingly jeopardised due to growing regional inequities, especially in the field of health care provision. Although Germany is a small country in the heart of Europe, rural areas are facing the challenge to ensure access to general practice and family medicine in remote areas. The natural turnover of elderly rural practitioners combined with the low level of recruitment and problems to retain health professionals in rural locations calls for immediate action.

International evidence shows that supporting medical careers in rural areas through undergraduate training is an effective means for reducing the rural exodus of physicians and preventing severe under supply of medical services in rural areas [3]. There is growing consensus among health scientists and politicians on the need to reorientate medical training towards family and rural medicine. However, a series of systemic, structural, institutional, political and ideological conditions make the necessary reforms and transformations difficult to implement. This paper analyses the most important constraints for effective policy measures to strengthen family and rural medicine and enhance the role of primary (health) care. Based on a short presentation of the German healthcare system, the paper will describe and discuss the most important constraints for strengthening primary care, which exist both at the decentralized institutional levels of the health sector and at medical schools.

\section{The German healthcare system}

Germany's healthcare system has been the pioneer of social health insurance, initiated as early as in 1881 under Chancellor Otto von Bismarck who lent his name to one of the basic types of health financing systems [4]. After stepwise expansion of both population coverage and benefit packages, health care in Germany is now universal with practically all residents covered by a comprehensive healthcare package with relatively low out-of-pocket payments. Despite its long tradition and often-envied level of accessible and affordable care, the German healthcare system and particularly the complex interaction of various decision makers is poorly understood abroad. The State decided to outsource a series of functions and responsibilities to decentralised self-governed institutions. This applies to both payers and providers: Statutory Health Insurance (SHI) (Gesetzliche Krankenversicherung) is responsible for enrolling beneficiaries and for collecting, pooling and allocating financial resources for health care; regional Statutory Health Insurance Physician Associations are mandatory for outpatient providers to be paid for treating SHI beneficiaries. Both institutions are regulated by public law, supervised by the Ministry of Health, autonomous, not-for-profit and selfgoverned. Despite the high level of autonomy, the specialised bodies are public in nature and have to negotiate all relevant arrangements including remuneration issues among themselves.

Everybody residing in Germany is mandated to take out health insurance, and entitlement to health benefits requires enrolment and regular contribution payment. Services are provided free of charge at the point of service except some minor co-payments. Practically $90 \%$ of the population living in Germany are enrolled into SHI where they can select among currently 120 funds. The contribution is basically 
shared between employer and employee (7.3\% of the salary each), but the latter pay on average an additional $1.1 \%$ on their own. Besides SHI, the better off with a yearly income above almost $€ 50,000$ (USD 54,000), self-employed, and civil servants for complementary coverage beyond the government employee benefit scheme, can opt for private health insurance (about $11 \%$ of the population). Both public and private health insurance funds provide a mandatory benefit package covering a broad scope of health services ranging from preventive care over highly specialised medical treatments to rehabilitation services.

\section{System constraints for strengthening general and rural health in Germany:}

Corporatism in the healthcare sector: The fact that Germany's healthcare sector is the archetype of a decentralised corporatist system has important implications for any strategy that aims at strengthening PHC. Since the state has delegated powers and decision-making competences to nongovernmental public bodies, implementing political decisions in daily practice is challenging and has to counterbalance diverging interests of the various stakeholders involved. SHI funds and provider organisations such as office-based SHI physicians' and dentists' associations or hospital federations are influential players within the German health sector. As the duty and power to decide upon benefits, prices, standards and other topics related to healthcare provision relies on self-governed "corporatist" bodies, imposing public policies is not a minor task. Although it is the job of legislators to promulgate laws, all regulations regarding outpatient care have to be agreed with the regional associations of panel physicians and SHI funds, and also among the latter [5].

Compared to countries with state-run or tax-borne healthcare systems, the stakeholder architecture in the German health sector seems to be more complex and also more suitable for championing the own interests and preventing policy impacts like strengthening PHC. SHI funds do not effectively strive for promoting PHC compared to other levels of care. The lack of integration between primary, secondary and tertiary services, and the duplication of specialist services in outpatient and inpatient care remain common, and the waste of resources persist [6]. As long as patients have the unrestricted choice of accessing medical care through general or specialist practice, all attempts to promote the use of generalist health services clash with people's freedom of physician choice that has become a highly relevant commodity among citizens in Germany [7].

In addition, the established working relations among the various health professions hamper a stronger role of primary care. German legislation defines physicians as the leading professional group in the healthcare sector; all other health experts can only provide diagnostic and therapeutic services on indication of a medical doctor. This reduces $\mathrm{PHC}$ to a large extent to general practice/ family medicine and prevents other health professions from playing a more proactive role in providing outpatient primary care. Implementing more participatory and interdisciplinary approaches in PHC calls for essential changes in the German health sector. Together with a series of other system features, the low level of service delegation to other health professionals contributes to the high number of patient contacts and short contact times of general practitioners in Germany [8].

The reforms required for implementing innovative models of healthcare provision, which are promising to tackle the arising challenges in general practice and particularly in rural health will inevitably create clashes with relevant stakeholders, particularly with physicians and their legal bodies. The prevailing role of medical doctors in healthcare provision is reflected in their predominant position in the health sector. This applies especially to outpatient care where panel physicians have shown much resistance to delegating medical services to nurses or medical assistants like in other countries, while they continuously complain about the workload generated by the high demand [9].

\section{Federalism in healthcare provision and academic institutions}

Germany is a federal republic composed by 16 federal states (Länder) that depict quite heterogeneous characteristics with regard to surface, population size, economic activity, income and others. While three of them are urban states and hence do not face the challenge to care for remote areas, others are relatively large and show a variable mix of urban and rural regions. Federalism is reflected in a number of political and institutional features and has strong impact on both healthcare and medical education in Germany. For instance, the federal states are responsible for regional hospital planning and for funding hospital infrastructure and investments. The former regional organisation of some large social health insurance has stepwise disappeared due to concentration and merging processes under the existing rules of competition [5].

The provision of outpatient care is organised statewise by regional Associations of Statutory Health Insurance Physicians, which are responsible for safeguarding access to healthcare in a defined area and for remunerating outpatient-care providers. All interventions, changes or reforms concerning PHC have to be negotiated with the regional representations of panel doctors, especially when it comes to agree upon financial responsibilities and obligations.

Federalism is also very strong in the German educational system since the responsibility for primary, secondary and tertiary education lies exclusively on the Länder. This means that all medical schools in Germany depend on regional governments; thus it is not an easy task to implement changes in any university training according to national priorities. The federal government cannot prescribe curricula, teaching and other elements of undergraduate training at national level; on the other hand, universities have - at least in theory - the chance to adapt their priorities and education to specific needs in the Land they belong to. But this is not always the case as shown below for the University of Magdeburg. With regard to strengthening PHC through adequate undergraduate training, national policies cannot be directly implemented in medical training unless federal state governments follow the respective guidelines voluntarily.

\section{Medical schools' focus on highly specialized care}

Despite some recent efforts to strengthen general practice during undergraduate training, medical schools in Germany currently exhibit an insufficient level of preparedness - and apparently also of willingness - to give adequate answers to the growing challenge of lacking family and general medicine and under-served rural regions. To a large extent, practical medical training occurs at university clinics and well-equipped hospitals providing (highly) specialised medical care instead of general practice and family medicine services. Due to traditional role models, social reputation, lacking opportunities to get into general practice and family medicine, and the revailing provider payment mechanisms, this condition is difficult to overcome. Moreover, a series of relevant structural changes corroborate the trend of medical schools to give family and rural health only a secondary or 
even tertiary role in undergraduate medical training. During the last 25 years, the business model of German universities - which are essentially public - has undergone fundamental changes: "Third-party resources" have replaced the hitherto budget financing through federal states [10]. The selection and appointment of professors and university teachers does not depend only on academic and professional reputation but increasingly also on the ability to access third party funding. Moreover, the academic world has increasingly become evermore competitive and market driven [11]. External demands, marketisation trends, opportunities to publish in ranked journals and even the obsession of researchers to make themselves mark interfere with the options to set priorities according to public needs and social accountability.

The University of Mag deburg is a shining example for the huge distance that often exists between academic research and real-life needs. Magdeburg is the capital of one of the economically least developed Länder with limited options to grow, a number of rather remote rural areas, demographic ageing enhanced by rural exodus, and a generally low level of education [12]. Nonetheless, the university in the region has decided to put priority on scientific research in two areas, namely immunology and neurosciences. Basic research is indispensable for developing and applying new diagnostic and therapeutic pathways and ultimately improving medical care. But for the University of Magdeburg in a rather poor federal state the use of limited resources raises some questions [13]. The need to acquire third-party financing from public institutions that have an interest in promoting the Länder of former East-Germany and from private companies, which also receive subsidies for investing in lower developed regions, is a strong driver for academic institutions to stand out for biomedical excellency in specific areas. Likewise, personnel decisions together with ambitions and the general climate in the academic world mainly driven by publication pressure, reputation and individual pretentions, but also by competition, favouritism and particularly by main-stream trends matter. Actually, a positive feedback loop between the endeavour for third party funding and the struggle for scientific reputation makes the medical academic system susceptible to loosing contact with real health needs over time.

Furthermore, the general conditions of university research force academics sometimes into linkages rather due to political economy than to appropriateness or rationality. The priority focus of the University of Magdeburg on neurosciences induced the Institute of General Practice and Family Medicine to initiate a research project on "Dementia in research and practice" together with a highly specialised centre. The objective to improve linkages between basic research and outpatient generalist care is understandable but unrealistic for two reasons: Early detection and effective treatment of dementia remain major challenges, and much basic research is still required before neuroscientists can offer something to general practice. The rationale behind this cooperation is to create links with "fashionable" topics and adapt to priority setting of the medical school. Research for general medical health care, however, should rather look into the gaps between clinical study results and daily life for well-established medical treatments.

Instead, the focussed and highly specialised orientation of medical schools restricts the space for research on the most pressing challenges of general and family medicine and relevant topics of health services research in the region. Priority setting in the field of medical research is hardly appropriate for improving undergraduate medical training and even less for tackling the major health needs in Länder like
Saxonia-Anhalt. Rethinking and reforming medical school design and orientation are needed in order to make clinical research, health care services and also undergraduate medical training more suitable to the current and future demand. Highly specialised and focalized research will not contribute to overcome current constraints and challenges such as overspecialization of health care and underservicing in rural areas. Both academic and political decision makers will have to promote necessary reforms, adapt the self-referential academic system to real-world needs, and provide adequate incentives for needs-based medical research and training. An innovative undergraduate medical training course implemented by the Institute of General Practice and Family Medicine of the University of Magdeburg in Germany has recently started in order to improve the potential of medical training to improve the health care in rural areas.

\section{New strategy towards recruiting rural physicians: "two- weekend programme" of elective, undergraduate rural practice course in Northern Saxony-Anhalt}

Based on the assessment of system constraints for strengthening PHC and deficiencies of medical training in preparing students adequately for rural medical practice, the Institute of General Practice and Family Medicine at the University of Magdeburg developed a comprehensive rural-health programme. The new "two-weekend programme" takes into account international evidence and experiences in creating interest and encouraging students to work in rural practice before they graduate. During the summer semester 2014, the twoweekend programme on rural practice started for the first time in order to teach skills of rural medical practice, enable the reflection of professional and personal goals, and immerse or even engage students in rural life [14]. In 2015, the second round of the two-weekend elective took place between May and June.

The course comprises a full programme according to participants' expectations and questions and applies a series of didactic tools such as presentations, interviews and discussions for bringing students closer to rural medical practice. Moderated discussions with various practitioners running different forms of rural practice in the region provide positive role models by talking about their professional work in different practice settings, informing about their motives, everyday experiences and their work-life balance, and discussing about issues for post-graduate education, future establishment and forms of employment. Students have the opportunity to discuss the "life-world" context of their later medical practice in terms of "life and work". According to Habermas' social theory grounded in communication, the life-world ("Lebenswelt" in German) signifies the lived realm of informal, culturally-grounded understandings and mutual accommodations. Rationalisation and colonization of the life-world by the instrumental rationality of bureaucracies and market-forces is a primary concern of Habermas' theory of communicative action. The concept of "life-world" emphasises a state of affairs in which the world is experienced and "lived" ("erlebt" in German) [15]. The experience of different rural doctors' life and work concept provides the participants of the elective with an idea of the social importance of their professional practice in contrast to the technical rationality, which prevails in systems of instrumentality such as the medical industrial complex in the context of tertiary and quaternary care of the university clinic.

During the weekend courses, students have excellent opportunities to train specific communication skills for patient management and long-term care of patients or their families in the community, 
particularly with regards to interview techniques and empathic patient conversation skills. Discussions about structural issues of rural medical offices, necessary skills, workload and possible coping strategies of rural healthcare professionals complement the programme. Likewise students have the opportunity to get into practical skills such as manual therapy and yoga offered by physiotherapists. Furthermore, the presentation and discussion of international experiences in medical training for rural practice replenishes the courses. After the twoweekend courses students are required to make a short evaluation of the various topics covered during the electives and to reflect on their experiences.

The assessment performed directly after the second weekend exhibits that the likelihood of future rural practice tends to increase substantially among practically all participants. Students particularly appreciate the diversity of topics and the seminar-like weekend courses outside the faculty and where calmer and more focused reflections are possible, especially with regard to students' own future career and life plans. Despite the overall positive impression of participants, organisers and the encouraging survey results, the future of the programme seems to be unclear and some changes have been suggested for future electives.

Critics refer to the fact that the "alternative" ecovillage is not representative for other rural communities in Saxonia-Anhalt, but it is an innovative project for rural settlement in a state with a shrinking, aging population. The Institute of General Practice itself is still balancing priority setting between preparing students for overall general practice and a particular focus on the rural-practice track. Despite irrefutable shortage of rural practitioners, general practice and particularly rural health needs are still far away from being priority of the Magdeburg medical school, which is still dominated by tertiary and quaternary hospital care and largely overwhelmed by highly specialised basic research concentrated in two centres of Neurosciences and Immunology. Therefore the commitment of the whole faculty teaching staff to rural practice is indifferent, at best, or even negative towards community based teaching and research. And Last but not least, the interest of medical students in rural practice still offers much room for improvement, and selective awarding of medical school places to students with rural background is not yet in sight.

\section{Conclusions and Outlook}

After more than 130 years of setting up a high-quality universal healthcare system, Germany faces increasing challenges to maintain its outstanding level of medical care in rural areas. Strengthening PHC and general practice is a promising strategy for safeguarding high standards of care for reasonable costs [16]. The German healthcare system, however, is characterised by a series of particularities that tend to hamper political priority setting and technical changes favouring primary care. The corporatist health sector comprises a series of influential actors with different interests that are often rather in favour of specialised than primary care. Federalism is another strong factor in the German political system that makes it more challenging to implement political changes at national level; this applies not only to the health sector as such but also to the education system including medical schools.

Like elsewhere, undergraduate medical training in Germany has a strong focus on (highly) specialised medical care while positive role models of general and rural practitioners are virtually absent. For attracting physicians to areas that currently have difficulty recruiting and/or retaining them, however, medical schools are required to provide training in rural practice and community engagement which gives graduates the confidence and skills for working and living in rural areas. During the summer semesters 2014 and 2015, the Institute of General Practice and Family Medicine at the University of Magdeburg realized the first elective rural-practice courses in a rural area of Germany. Preliminary evaluation results show an increased willingness to go for a professional life in rural areas after graduation. The evaluation also shows a positive effect on the interest of those students, who can imagine a future career in the rural area, seeking a link between medical professionalism and life-world aspects, as a life with family and children in a community. It suggests that their career plans significantly differ from the ones of their fellow students who are primarily looking for an academic career in the scientific and university medicine. Therefore it is important for the further development of undergraduate medical training that students are not restricted to the role models of clinical and theoretical scientists; already at an early stage of their studies they need to get in touch with rural practitioners, who have set up their professional and private life in a rural context. Although a follow-up assessment will further determine the outcomes of such a short course in rural practice, the approach taken by the University of Magdeburg seems to corroborate international findings that the contact with rural practice at an early stage of undergraduate training has the potential to improve the recruitment of rural medical professionals. Germany has still to learn more from longer experiences of other countries, which have implemented continuous learning through rural practice, community engagement and social accountability of health care and the medical education [17].

\section{References}

1. Schoen C, Osborn R, Squires D, Doty M, Pierson R, et al. (2011) New 2011 survey of patients with complex care needs in eleven countries finds that care is often poorly coordinated. Health Aff (Millwood) 30: 2437-2448.

2. Jankauskie D, Jankauskait I (2011) Access and Quality of Health Care Systems by Opinion of Patients in Ten European Countries. Management in Health 15: 31-39.

3. WHO (2015) Increasing Access to health workers in remote and rural areas through improved retention. Global Policy Recommendations. Geneva: World Health Organization.

4. Bump J (2015) The Long Road to Universal Health Coverage: Historical Analysis of Early Decisions in Germany, the United Kingdom, and the United States. Health Systems \& Reform 1: 28-38.

5. Busse R, Blümel M (2014) HiT Germany. Health Systems in Transition 16 (2) Copenhagen: WHO EURO.

6. Vuori H (1986) Health for all, primary health care and general practitioners. J R Coll Gen Pract 36: 398-402.

7. Clade H (1999) Freie Arztwahl - für den Patienten unverzichtbar. Deutsches Arzteblatt 96: A676.

8. Koch K, Miksch A, Schürmann C, Joos S, Sawicki PT (2011) The German health care system in international comparison: the primary care physicians' perspective. Dt Arztebl Int 108: 255-261.

9. Koch K, Gehrmann U, Sawicki P (2007) Primary Care in Germany-an International Comparison. Dt Arztebl 104: A - 2584.

10. Meyborg M (2013) The role of German universities in a system of joint knowledge generation and innovation. Dissertation, Karlsruher Institut für Technologie, Fakultät für Wirtschaftswissenschaften. Karlsruhe: KIT Scientific Publishing.

11. Hummers-Pradier E, Bleidorn J, Schmiemann G, Joos S, Becker A, et al. (2012) General practice-based clinical trials in Germany-a problem analysis. Trials 13: 205. 
Citation: Holst H, Herrmann M (2016) Structural Challenges for Improving Rural Medical Training in Germany. J Health Edu Res Dev 4: 154. doi: $10.4172 / 2380-5439.1000154$

Page 5 of 5

12. ISW (2014) Sozioökonomische Analyse inkl. SWOT for the ERDF, ESF and EAFRD Saxony-Anhalt 2014-2020. Halle/Magdeburg: Institut gGmbH for structural policy and Wirtschaftsförderung.

13. Marx Y, von Hintzenstern J, Eich-Krohm A, Robra BP, Herrmann ML (2015) (Früh-) Erkennung demenzieller Erkrankungen aus hausärztlicher Sicht - Ergebnisse des Projektes NEUROTRANS ((Early) detection of dementia from a general-practitioner perspective - Results of the NEUROTRANS project). Gesundheitswesen 77: A214.

14. Herrmann M, Hänel P, Jansen E (2014) Landärztliche Ausbildung zur Reduzierung der medizinischen Unterversorgung auf dem Land -
Erfahrungen, Chancen, Widrigkeiten. In: Jahrbuch für kritische Medizin und Gesundheitswissenschaften, Primary Health Care Hamburg: Argument 50: 144 -172.

15. Habermas J (1987) Theory of Communicative Action. Volume Two: Liveworld and System: A Critique of Functionalist Reason. Boston: Beacon Press.

16. Starfield B (1994) Is Primary Care Essential? Lancet 344: 1129-33.

17. Strasser R (2010) Community engagement: a key to successful rural clinical education; Rural Remote Health 10: 1543. 